\title{
CLOSING OF COSTER-KRONIG TRANSITIONS AND VARIATION OF FLUORESCENCE AND AUGER YIELDS IN ISONUCLEAR SEQUENCE OF TUNGSTEN
}

\author{
S. Kučas and R. Karazija \\ Institute of Theoretical Physics and Astronomy of Vilnius University, A. Goštauto 12, LT-01108 Vilnius, Lithuania \\ E-mail: sigitas.kucas@tfai.vu.lt
}

Received 25 July 2011; accepted 21 September 2011

\begin{abstract}
The dependence of Auger yields, partial and total Auger widths of levels, total radiative widths, and fluorescence yields on the ionisation degree is considered for ions of tungsten. The calculations are performed for the $\mathrm{N}_{i}$ subshells in the single configuration quasirelativistic approximation. The intervals of ionisation stages at which the Coster-Kronig transitions are energetically possible or partially possible are determined. It is shown that the partially possible Coster-Kronig transitions between overlapping initial and final configurations can take place in several neighbouring ions successively. According to our calculation results, the nonradiative decay of vacancies in $\mathrm{N}_{i}$ subshells becomes impossible from ionisation stage $q=21$. The total Auger width depends weakly on ionisation degree up to its values $q=8-11$, but for higher ions changes non-monotonically due to closing of Coster-Kronig transitions. The fluorescence yield shows the similar dependence on $q$.
\end{abstract}

Keywords: Coster-Kronig transitions, Coster-Kronig yield, fluorescence yield, Auger width, tungsten ions

PACS: $31.10 .+\mathrm{z}, 32.80 . \mathrm{Hd}, 32.70 . \mathrm{Jz}$

\section{Introduction}

Systematic calculations of Auger transitions are mainly restricted by atoms with a single vacancy in an inner shell [1, 2]. Extensive tables of Coster-Kronig and fluorescence yields, Auger and total natural level widths are published and their regularities are established [3-7]. For investigations of Auger cascades after production of inner vacancy and of the rearrangement of electronic shells after atom-ion collisions, required fluorescence and Auger yields for ions are usually derived from the available rates for the single vacancy atoms [8, 9]. For this purpose the scaling procedure for the total Auger transition rates [10] is used. These quantities are expressed in terms of a coefficient containing all the dependence on numbers of electrons in shells or subshells and a reduced transition rate depending only on radial wave functions and quantum numbers of electrons involved in the transitions. The total rate for a higher ionisation degree is calculated by taking the other numbers of electrons in the shells and supposing the second factor is constant or by linearly extrapolating the latter. However, the closing of some low energy Auger transitions can substantially change the fluorescence and Auger yields [11]. It is checked usually from the aver- age energy calculations for considered configurations. This method does not take into account the partial overlap of energy level spectra of initial and final configuration as well as the strong dependence of the radial integrals on the Auger electron energy.

Nowadays the extensive investigations of astrophysical and laboratory plasma, of Auger cascades in atoms require the consideration of Auger transition regularities in multi-charged ions. Such data are necessary also for the interpretation of emission spectra of ions. Radiative and nonradiative transitions are tightly related as competitive, interdependent processes, their relative role is determined by the value of fluorescence yield. In the spontaneous decay of ion states with vacancies the nonradiative Auger transitions often dominate and they give the main contribution to the natural level widths, which are necessary for the calculation of radiative transitions intensities.

The ions of tungsten have been selected as an exemplary object for investigation of Auger transitions regularities in isonuclear sequence due to interest in its spectroscopic properties. This element is used as a first wall material in the last generation tokamaks. However, some quantities of tungsten are sputtered from the divertor surface and migrate into the region of discharge. 
The multi-electron ions present in tokamak plasma can cause large radiation power loss [12]. We will consider the Auger transitions, mainly the most probable Coster-Kronig (CK) and super-Coster-Kronig (sCK) transitions, from the initial states with vacancies in the shells with the principal quantum number $n=4$. Such vacancies are effectively produced at the conditions in tokamak plasma [13]. We suppose that the case of tungsten can reveal some general regularities of $\mathrm{CK}$ and fluorescence yields variation in isonuclear sequence.

\section{Method of calculation}

The calculations have been performed in the quasirelativistic approximation [14], which is widely used for the investigation of spectral characteristics of tungsten ions $[15,16]$. The average quantities depend less than the characteristics of separate transitions on the accuracy of the approximation used, thus in our work such quantities were calculated in a single configuration approximation. The radial integrals were not diminished by scaling factors, because their recommended values vary with $q$ nonmonotonically and that would distort the dependence of considered quantities on the ionisation degree.

For outer and subvalent shells of considered ions the quasirelativistic single configuration approximation is preferable over the relativistic one, because the former takes into account main relativistic corrections and also includes interaction among relativistic $n l j$-configurations, corresponding to the same $n l$ configuration. On the other hand, the partitioning of shells into subshells enables one to obtain the average characteristics of subshells or of transitions between subshels, thus such scheme is more appropriate and habitual in inner-shell physics. For configurations with single vacancies in the closed shells it is possible to reconcile the advantages of both schemes: to perform calculations for $n l$-configurations, but afterwards to distinguish the groups of levels corresponding to $n l j$-configurations. For vacancies in inner shells such groups can be separated energetically. Even for partially overlapping energy level spectra with different values of total angular momentum of vacancy such separation can be performed by classification of states according to the largest weight in the expansion of the wave functions in $j j$ coupling scheme. However, such attribution becomes invalid at strong mixing of wave functions, when $n l j$-configurations strongly overlap.

We attempted to preserve $j j$ classification where it was possible. For this purpose the energy matrices were calculated and the wave functions classified in this scheme. The traditional for inner-shell physics notations of subshells with the principle quantum number $n=4\left(\mathrm{~N}_{i}\right)$ are used.

The ground configurations of tungsten ions were taken from the latest revised data [17], they coincide with configurations obtained in single configuration quasirelativistic approximation, except $q=12$, where the calculation gives the lowest level corresponding to a $4 f^{13} 5 s^{2} 5 p$ configuration instead of a $4 f^{14} 5 s^{2}$ configuration following from experimental data.

During CK transitions the free electron escapes with a small energy, thus the rates of such transitions can depend strongly on the free electron energy $\varepsilon$. The example of very strong dependence of radial integrals of Auger transitions on the $\varepsilon$ value can be sCK transition $\mathrm{N}_{2}-\mathrm{N}_{3} \mathrm{~N}_{6,7}$ : values of integrals $R^{2}(4 p 4 f, 4 p \varepsilon f)$ and $R^{2}(4 p 4 f, \varepsilon f 4 p)$ increase twice in the interval of spectrum equal to about $20 \mathrm{eV}$. These integrals also show an unusual dependence on $\varepsilon$. The oscillation of free electron wave function $P_{\varepsilon l}(r)$ increases with $\varepsilon$, thus the absolute value of Auger radial integrals $R^{k}$ usually tends to decrease. However, for some transitions the absolute value of $R^{k}$ can increase within some interval of small values of $\varepsilon$; the reason of such behaviour is the varying overlap between wave functions of electrons contained in this integral. Then the usual tendency manifests itself only at larger values of $\varepsilon$. Such is the indicated case.

In order to take into account the dependence of transition rates on the energy of Auger electron, we used the following procedure. The Auger transition integrals were calculated for seven equidistant values of $\varepsilon$ within its interval for one channel of considered Auger transitions. Then the contribution to total Auger transition rate [18] was calculated for these values of $\varepsilon$ and the average energy of Auger electron determined as follows:

$$
\varepsilon_{\mathrm{av}}=\frac{\sum_{i} \varepsilon_{i} A_{i}}{\sum_{i} A_{i}}
$$

where $A_{i}$ is the total transition rate for the $i$ th value of $\varepsilon$ and $i$ runs from 1 to 7 . Subsequently all contributions to total transition rates were recalculated with this one $\varepsilon_{\text {av }}$ value.

In the case of overlapping initial and final configurations the detailed level-by-level calculations for energetically allowed Auger transitions were performed, taking the radial integrals calculated at the middle value of the allowed energy interval. 
Table 1. Intervals of ionisation stages of tungsten ions, where $\mathrm{N}_{i} N_{j} X$ Coster-Kronig and $\mathrm{N}_{i} N_{j} N$, superCoster-Kronig transitions are possible (p) or partially possible (pp)

\begin{tabular}{|c|c|c|c|c|c|c|c|c|c|c|c|}
\hline \multirow{3}{*}{$\begin{array}{l}\text { Final } \\
\text { vacancy } \\
\text { state }\end{array}$} & \multicolumn{11}{|c|}{ Initial vacancy state } \\
\hline & \multicolumn{2}{|c|}{$\mathrm{N}_{1}$} & \multicolumn{2}{|c|}{$\mathrm{N}_{2}$} & \multicolumn{2}{|c|}{$\mathrm{N}_{3}$} & \multicolumn{2}{|c|}{$\mathrm{N}_{4}$} & \multicolumn{2}{|c|}{$\mathrm{N}_{5}$} & \multirow[t]{2}{*}{$\mathrm{N}_{6,7}$} \\
\hline & $\mathrm{p}$ & $\mathrm{pp}$ & $\mathrm{p}$ & $\mathrm{pp}$ & $\mathrm{p}$ & $\mathrm{pp}$ & $\mathrm{p}$ & $\mathrm{pp}$ & $\mathrm{p}$ & $\mathrm{pp}$ & \\
\hline $\mathrm{N}_{2,3} \mathrm{~N}_{2,3}$ & - & - & - & - & - & - & - & - & - & - & - \\
\hline $\mathrm{N}_{2,3} \mathrm{~N}_{4,5}$ & - & - & - & - & - & - & - & - & - & - & - \\
\hline $\mathrm{N}_{2} \mathrm{~N}_{6,7}$ & $1-3$ & 4 & - & - & - & - & - & - & - & - & - \\
\hline $\mathrm{N}_{2} \mathrm{O}_{1}$ & - & $1-2$ & - & - & - & - & - & - & - & - & - \\
\hline $\mathrm{N}_{2} \mathrm{O}_{2,3}$ & $1-2$ & $3-5$ & - & - & - & - & - & - & - & - & - \\
\hline $\mathrm{N}_{2} \mathrm{O}_{4,5}$ & $1-6$ & - & - & - & - & - & - & - & - & - & - \\
\hline $\mathrm{N}_{2} \mathrm{P}_{1}$ & $1-2$ & - & - & - & - & - & - & - & - & - & - \\
\hline $\mathrm{N}_{3} \mathrm{~N}_{6,7}$ & $1-7$ & $8-9$ & - & $1-3$ & - & - & - & - & - & - & - \\
\hline $\mathrm{N}_{3} \mathrm{O}_{1}$ & $1-6$ & - & - & - & - & - & - & - & - & - & - \\
\hline $\mathrm{N}_{3} \mathrm{O}_{2,3}$ & $1-7$ & $8-10$ & - & $1-3$ & - & - & - & - & - & - & - \\
\hline $\mathrm{N}_{3} \mathrm{O}_{4,5}$ & $1-6$ & - & - & $1-4$ & - & - & - & - & - & - & - \\
\hline $\mathrm{N}_{3} \mathrm{P}_{1}$ & $1-2$ & - & - & $1-2$ & - & - & - & - & - & - & - \\
\hline $\mathrm{N}_{4,5} \mathrm{~N}_{4,5}$ & $1-3$ & 4-6 & - & - & - & - & - & - & - & - & - \\
\hline $\mathrm{N}_{4} \mathrm{~N}_{6,7}$ & $1-13$ & $14-15$ & $1-9$ & $10-12$ & $1-7$ & $8-9$ & - & - & - & - & - \\
\hline $\mathrm{N}_{4} \mathrm{O}_{1}$ & $1-13$ & $14-15$ & $1-8$ & $9-11$ & $1-5$ & - & - & - & - & - & - \\
\hline $\mathrm{N}_{4} \mathrm{O}_{2,3}$ & $1-12$ & - & $1-10$ & $11-12$ & $1-7$ & $8-9$ & - & - & - & - & - \\
\hline $\mathrm{N}_{4} \mathrm{O}_{4,5}$ & $1-6$ & - & $1-6$ & - & $1-6$ & - & - & - & - & - & - \\
\hline $\mathrm{N}_{4} \mathrm{P}_{1}$ & $1-2$ & - & $1-2$ & - & $1-2$ & - & - & - & - & - & - \\
\hline $\mathrm{N}_{5} \mathrm{~N}_{6,7}$ & $1-14$ & $15-16$ & $1-9$ & $10-12$ & $1-7$ & $8-10$ & - & - & - & - & - \\
\hline $\mathrm{N}_{5} \mathrm{O}_{1}$ & $1-14$ & $15-16$ & $1-8$ & $9-12$ & $1-6$ & - & - & - & - & - & - \\
\hline $\mathrm{N}_{5} \mathrm{O}_{2,3}$ & $1-12$ & - & $1-11$ & 12 & $1-7$ & $8-10$ & - & - & - & - & - \\
\hline $\mathrm{N}_{5} \mathrm{O}_{4,5}$ & $1-6$ & - & $1-6$ & - & $1-6$ & - & - & 1 & - & - & - \\
\hline $\mathrm{N}_{5} \mathrm{P}_{1}$ & $1-2$ & - & $1-2$ & - & $1-2$ & - & - & 1 & - & - & - \\
\hline $\mathrm{N}_{6,7} \mathrm{~N}_{6,7}$ & $1-19$ & $20-21$ & $1-17$ & $18-19$ & $1-14$ & $15-17$ & $1-8$ & $9-12$ & $1-8$ & $9-11$ & - \\
\hline $\mathrm{N}_{6,7} \mathrm{O}_{1}$ & $1-17$ & - & $1-17$ & - & $1-15$ & $16-17$ & $1-7$ & $8-10$ & $1-7$ & $8-10$ & - \\
\hline $\mathrm{N}_{6,7} \mathrm{O}_{2,3}$ & $1-12$ & - & $1-12$ & - & $1-12$ & - & $1-9$ & $10-12$ & $1-9$ & $10-12$ & - \\
\hline $\mathrm{N}_{6,7} \mathrm{O}_{4,5}$ & $1-6$ & - & $1-6$ & - & $1-6$ & - & $1-6$ & - & $1-6$ & - & - \\
\hline $\mathrm{N}_{6,7} \mathrm{P}_{1}$ & $1-2$ & - & $1-2$ & - & $1-2$ & - & $1-2$ & - & $1-2$ & - & - \\
\hline
\end{tabular}

\section{Results and discussion}

The energy level spectra of configurations with vacancies in $\mathrm{N}_{i}$ subshells and outer open shells extend up to several tens of eV. Thus the case of overlapping initial and final configurations is rather frequent. The intervals of ionisation stages at which the CK transitions are energetically possible or partially possible are indicated in Table 1. The partially possible transitions between some levels of overlapping configurations can extend in the sequence of ions even up to 4 successive values of $q$. It is necessary to note that the interval of CK spectrum, where intensities of lines obtain practically significant values, can be noticeably narrower than the interval of energetically possible transitions.

With increasing the ionisation degree the transitions become impossible due to the absence of electrons in the shells involved in the transitions. Additionally, the CK transitions with a small energy of Auger electron can become energetically forbidden with increasing atomic number of an element. The same regularity manifests itself with increasing the ionisation degree $q$. It follows from the expression for the energy of Auger transition in terms of binding energies of three electrons involved in the transition. The sum of binding energies of two such electrons present in the initial configuration of CK transition can be changed to a larger extent than the binding energy of the electron present in the final configuration. The nonradiative decay of $\mathrm{N}_{2,3}$ vacancy states becomes impossible from ionisation stage 19 and of $\mathrm{N}_{1}$ states from $q=21$.

CK yield $S_{i, j}$ is defined as the probability that a vacancy in the subshell $X_{i}$ is shifted to the subshell $X_{j}$ during the $\mathrm{CK}$ transition, while the other vacancy is produced in the same or other subshell:

$$
S_{i, j}=\frac{\sum_{k} A_{\mathrm{CK}}\left(X_{i}-X_{j} X_{k}\right)[1+\delta(j, k)]}{A_{\mathrm{tot}}\left(X_{i}\right)},
$$

where $A_{\mathrm{CK}}$ is the CK transition rate and $A_{\text {tot }}$ is the total Auger and radiative transitions rate for the state with initial vacancy. The last multiplier in the nominator takes into account the possibility for both vacancies 
Table 2. Coster-Kronig $\mathrm{N}_{i}$ yields for tungsten ions

\begin{tabular}{|c|c|c|c|c|c|c|c|c|c|c|c|c|c|c|}
\hline $\begin{array}{c}\text { Ionisation } \\
\text { degree }\end{array}$ & $S_{1,2}$ & $S_{1,3}$ & $S_{1,4}$ & $S_{1,5}$ & $S_{1,67}$ & $S_{2,3}$ & $S_{2,4}$ & $S_{2,5}$ & $S_{2,67}$ & $S_{3,4}$ & $S_{3,5}$ & $S_{3,67}$ & $S_{4,67}$ & $S_{5,67}$ \\
\hline 1 [7] & 0.19 & 0.56 & 0.062 & 0.092 & 0.59 & 0.114 & 0.67 & 0.10 & 0.79 & 0.14 & 0.73 & 0.82 & 1.7 & 1.73 \\
\hline 1 & 0.187 & 0.538 & 0.068 & 0.102 & 0.521 & 0.068 & 0.715 & 0.107 & 0.803 & 0.122 & 0.719 & 0.646 & 1.662 & 1.620 \\
\hline 2 & 0.186 & 0.538 & 0.073 & 0.100 & 0.522 & 0.017 & 0.757 & 0.112 & 0.804 & 0.122 & 0.720 & 0.650 & 1.664 & 1.622 \\
\hline 3 & 0.186 & 0.544 & 0.068 & 0.101 & 0.527 & 0.006 & 0.765 & 0.114 & 0.811 & 0.123 & 0.718 & 0.650 & 1.666 & 1.624 \\
\hline 4 & 0.149 & 0.566 & 0.072 & 0.107 & 0.554 & 0.005 & 0.765 & 0.114 & 0.814 & 0.122 & 0.717 & 0.654 & 1.679 & 1.641 \\
\hline 5 & 0.032 & 0.643 & 0.084 & 0.125 & 0.614 & & 0.768 & 0.116 & 0.822 & 0.123 & 0.715 & 0.664 & 1.692 & 1.652 \\
\hline 6 & 0.018 & 0.658 & 0.089 & 0.132 & 0.637 & & 0.768 & 0.116 & 0.823 & 0.110 & 0.723 & 0.680 & 1.713 & 1.678 \\
\hline 7 & & 0.642 & & & 0.722 & & 0.767 & 0.118 & 0.835 & 0.120 & 0.696 & 0.753 & 1.736 & 1.699 \\
\hline 8 & & 0.340 & & & 0.596 & & 0.760 & 0.122 & 0.809 & 0.083 & 0.633 & 0.662 & 1.696 & 1.672 \\
\hline 9 & & 0.005 & & & 0.840 & & 0.761 & 0.141 & 0.878 & 0.009 & 0.315 & 0.831 & 1.825 & 1.837 \\
\hline 10 & & & & & 0.866 & & 0.770 & 0.140 & 0.946 & & & 1.260 & 1.898 & 1.804 \\
\hline 11 & & & & & 0.893 & & 0.484 & 0.272 & 0.939 & & & 1.330 & 1.043 & 0.994 \\
\hline 12 & & & & & 0.854 & & 0.031 & 0.112 & 1.233 & & & 1.297 & 0.702 & 0.556 \\
\hline 13 & & & & & 0.970 & & & & 1.783 & & & 1.643 & & 1.620 \\
\hline 14 & & & & & 0.937 & & & & 1.756 & & & 1.605 & & \\
\hline 15 & & & & & 1.169 & & & & 1.727 & & & 1.564 & & \\
\hline 16 & & & & & 1.350 & & & & 1.689 & & & 1.282 & & \\
\hline 17 & & & & & 1.546 & & & & 1.816 & & & 1.000 & & \\
\hline 18 & & & & & 2.000 & & & & & & & & & \\
\hline 19 & & & & & 2.000 & & & & & & & & & \\
\hline 20 & & & & & 2.000 & & & & & & & & & \\
\hline 21 & & & & & 2.000 & & & & & & & & & \\
\hline
\end{tabular}

to appear in the same $X_{j}$ subshell by sCK transitions $X_{i}-X_{j}^{2}$. Thus in the presence of such transitions the yield $S_{i, j}$ can obtain a value greater than 1 . The values of these quantities for various subshells are presented in Table 2. Only for single ions our results can be compared with the values of previous calculations [19] obtained in nonrelativistic approximations [20] (recently published data [7] employ the same results [19] fitted to polynomials as a function of atomic number). The differences of nonrelativistic and quasirelativistic calculations for single ions are not significant.

Nonradiative transitions dominate in the decay of vacancies in the $\mathrm{N}_{i}$ subshells of tungsten, thus the Auger width is practically equal to the natural width $\Gamma\left(N_{i}\right)$. For low ionisation degrees the calculated values for $\mathrm{N}_{1}$, $\mathrm{N}_{2,3}$, and $\mathrm{N}_{4,5}$ vacancy states amount to several $\mathrm{eV}$ and even exceed $10 \mathrm{eV}$ (Fig. 1). In the sequence of ions the Auger width almost does not depend on ionisation degree $q$ while Auger transitions remain energetically possible. At ionisation stages $q=6-11$ the sudden decrease of Auger width takes place due to energetic interdiction of the CK transitions.

The calculated widths can be compared with experimental values as well as with results of calculations in various approximations, compiled for single ions in [6] (Table 3). Our results correspond better to experimental values than those calculated by relativistic Dirac-Fock-Slater [21] or nonrelativistic Hartree-

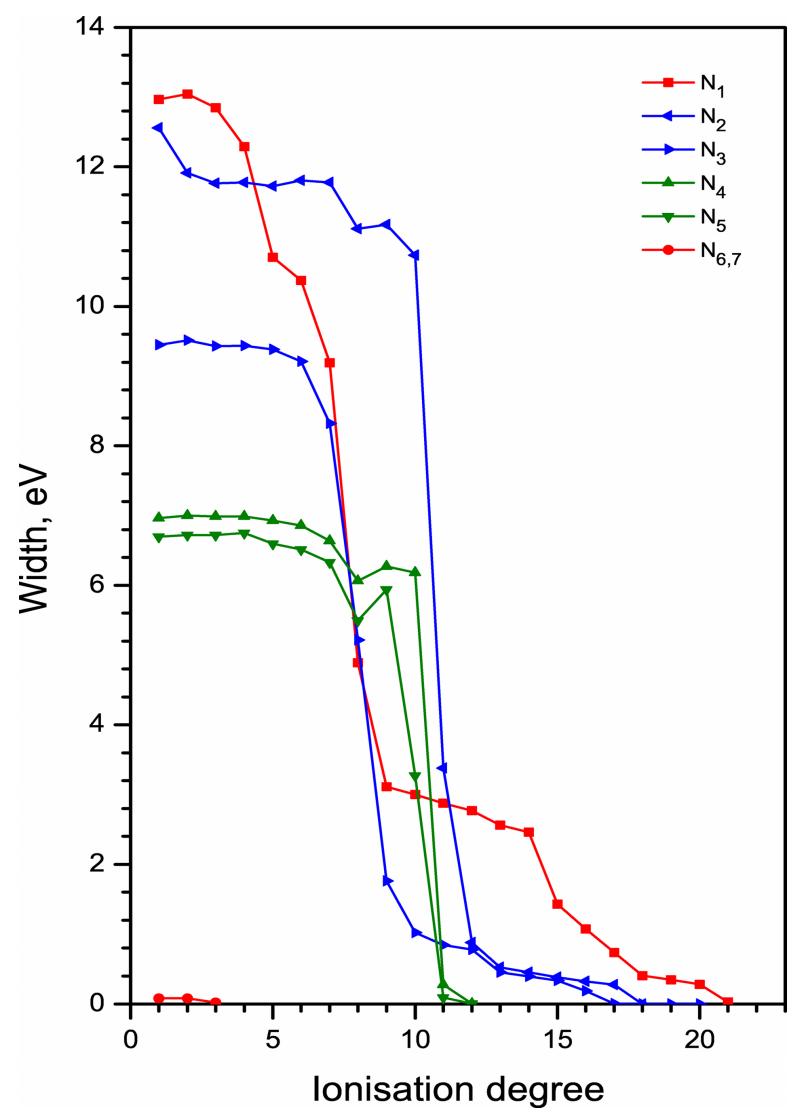

Fig. 1. Dependence of $\mathrm{N}_{1}, \mathrm{~N}_{2}, \mathrm{~N}_{3}, \mathrm{~N}_{4}, \mathrm{~N}_{5}$ and $\mathrm{N}_{6,7}$ Auger widths on ionisation degree. 
Table 3. Auger widths for tungsten atom with one vacancy. Comparison of results, calculated in quasirelativistic (RHF) approximation with the values obtained in DiracFock-Slater (DFS), Hartree-Fock-Slater (HFS), many-bodyperturbation theory (MBPT) approximations and experimental data.

\begin{tabular}{cccccc}
\hline Subshell & $\begin{array}{c}\text { Exp } \\
{[6]}\end{array}$ & $\begin{array}{c}\text { DFS } \\
{[21]}\end{array}$ & $\begin{array}{c}\text { HFS } \\
{[19]}\end{array}$ & $\begin{array}{c}\text { MBPT } \\
{[22]}\end{array}$ & $\begin{array}{c}\text { RHF } \\
\text { This work }\end{array}$ \\
\hline $\mathrm{N}_{1}$ & $7.4 \pm 1.6$ & 14.5 & 15 & & 12.97 \\
$\mathrm{~N}_{2}$ & $5.4 \pm 0.7$ & 13.6 & 13.8 & & 12.56 \\
$\mathrm{~N}_{3}$ & $4.7 \pm 0.8$ & 10 & 12.3 & & 9.45 \\
$\mathrm{~N}_{4}$ & $2.9 \pm 0.6$ & 7.3 & 7.89 & 3.41 & 7.14 \\
& $5.0 \pm 0.7$ & & & 4.61 & \\
$\mathrm{~N}_{5}$ & $3.1-5.0$ & 6.9 & 7.72 & 3.41 & 6.70 \\
$\mathrm{~N}_{6}$ & $0.16-0.09$ & & 0.07 & & \} 0.08 \\
$\mathrm{~N}_{7}$ & $0.11-0.19$ & & & & \} \\
\hline
\end{tabular}

Fock-Slater [19] methods. However, for all shells, except $\mathrm{N}_{6,7}$, single configuration calculation significantly overestimates experimental data. Good correspondence was obtained by application of many-body perturbation theory [22], but such results were given only for $\mathrm{N}_{4}$ and $\mathrm{N}_{5}$ subshells. It indicates the essential role of correlation effects for CK transitions, which significantly contribute to Auger width. However, the separation of rela-

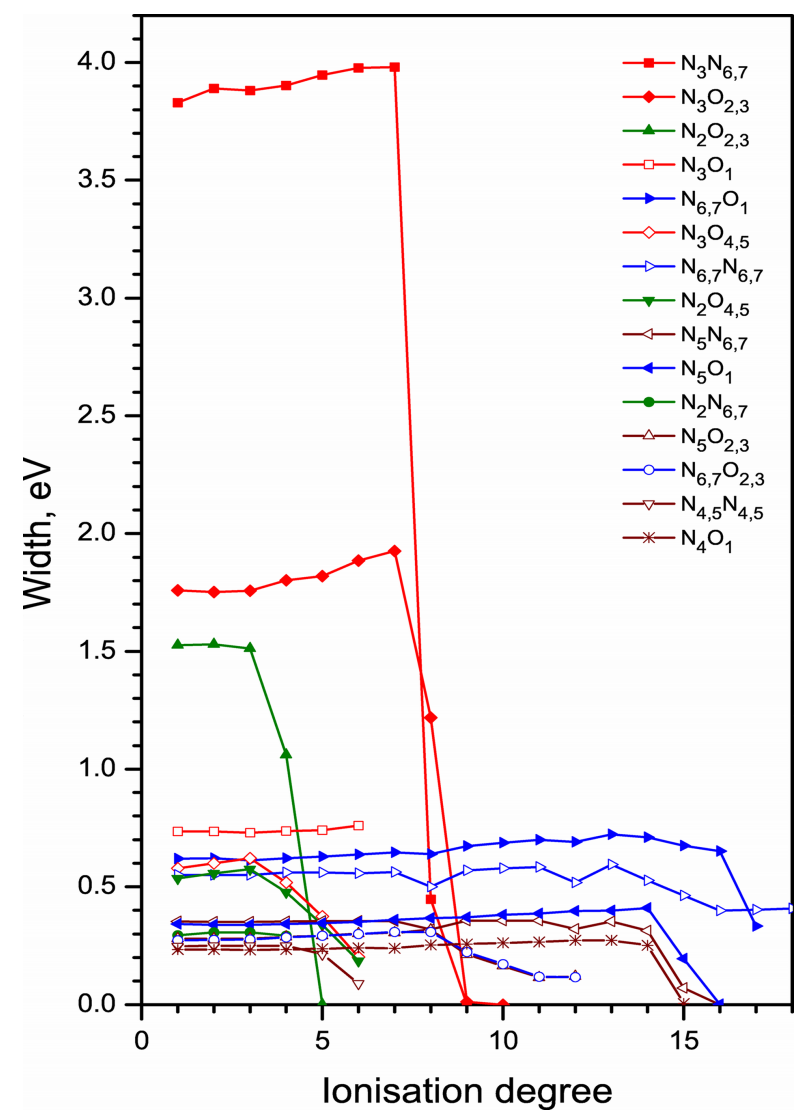

Fig. 2. Contributions of Coster-Kronig transitions to $\mathrm{N}_{1}$ Auger width at various ionisation degrees. Transitions which contribute less than $0.23 \mathrm{eV}$ for the first ion of sequence are not indicated. tivistic configurations tends to increase with $q$ and configuration interaction effects often become weaker for ions (with exceptions of some intersecting configurations). Thus a better correspondence of calculated and experimental results for higher ions can be supposed.

The near-independence of partial Auger width on $q$ and on the outer passive shell is clearly expressed up to the ionisation stages, when corresponding Auger transitions become energetically forbidden (Figs. 2 and 3). The decay of $\mathrm{N}_{i}(i=1-5)$ vacancy states is dominated by transitions involving $4 \mathrm{f}$ electrons. The largest contribution to $\Gamma\left(N_{1}\right)$ width is given by $\mathrm{N}_{1}-\mathrm{N}_{3} \mathrm{~N}_{6,7}$ transitions, but also $\mathrm{N}_{1}-\mathrm{N}_{3} \mathrm{O}_{2,3}$ and $\mathrm{N}_{1}-\mathrm{N}_{4,5} \mathrm{O}_{2,3}$ transitions play a significant role. For $\Gamma\left(N_{3}\right)$ almost half of the width is given by transitions to $\mathrm{N}_{5} \mathrm{~N}_{6,7}$, while transitions to $\mathrm{N}_{4} \mathrm{~N}_{6,7}$ dominate more in deexcitation of $\mathrm{N}_{2}$ vacancy state. In the case of $\Gamma\left(N_{4}\right)$ and $\Gamma\left(N_{5}\right)$ widths the contribution of transitions to $\mathrm{N}_{6,7}^{2}$ amounts already to about $2 / 3$ of the total width.

The total radial width $\Gamma_{\text {rad }}\left(N_{i}\right)$ varies slowly at low ionisation degrees, when the outer shells are ionised (Fig. 4). The reason of a sudden decrease of this quantity at $q=16$ for $\mathrm{N}_{2}$ and $\mathrm{N}_{3}$ vacancy states is

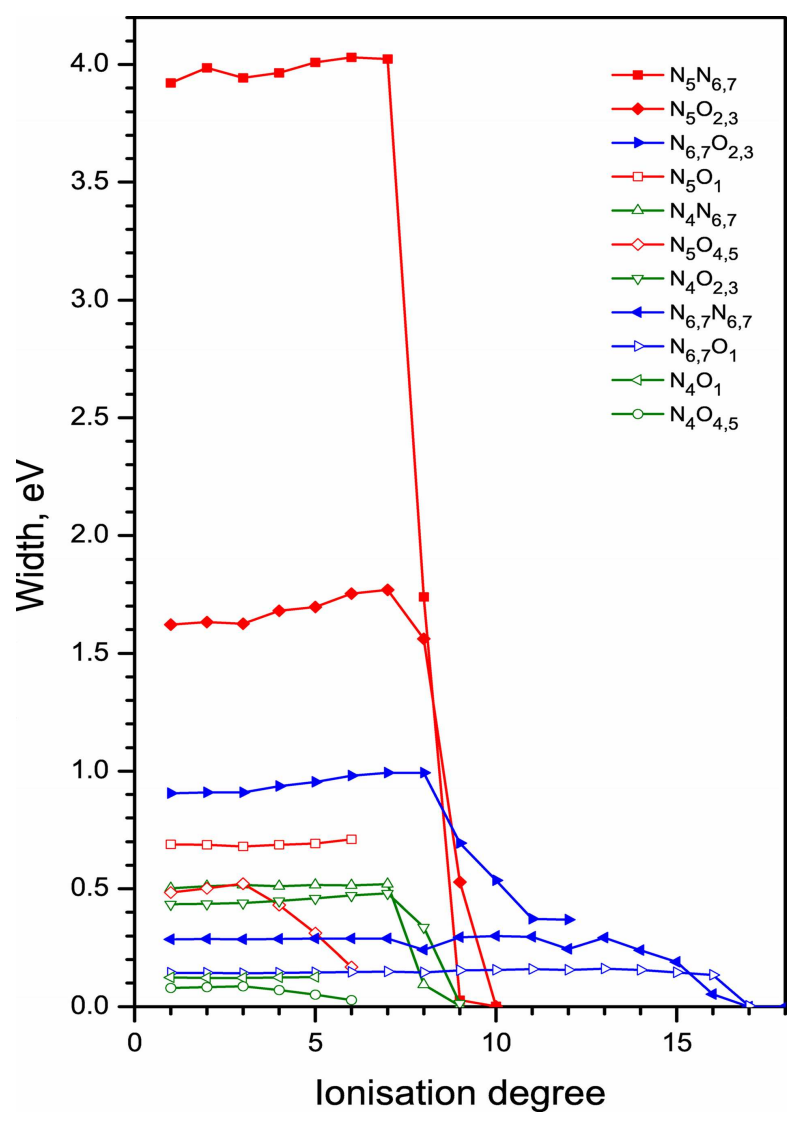

Fig. 3. Contributions of Coster-Kronig transitions to $\mathrm{N}_{3}$ Auger width at various ionisation degrees. Transitions which contribute less than $0.075 \mathrm{eV}$ for the first ion of sequence are not indicated. 


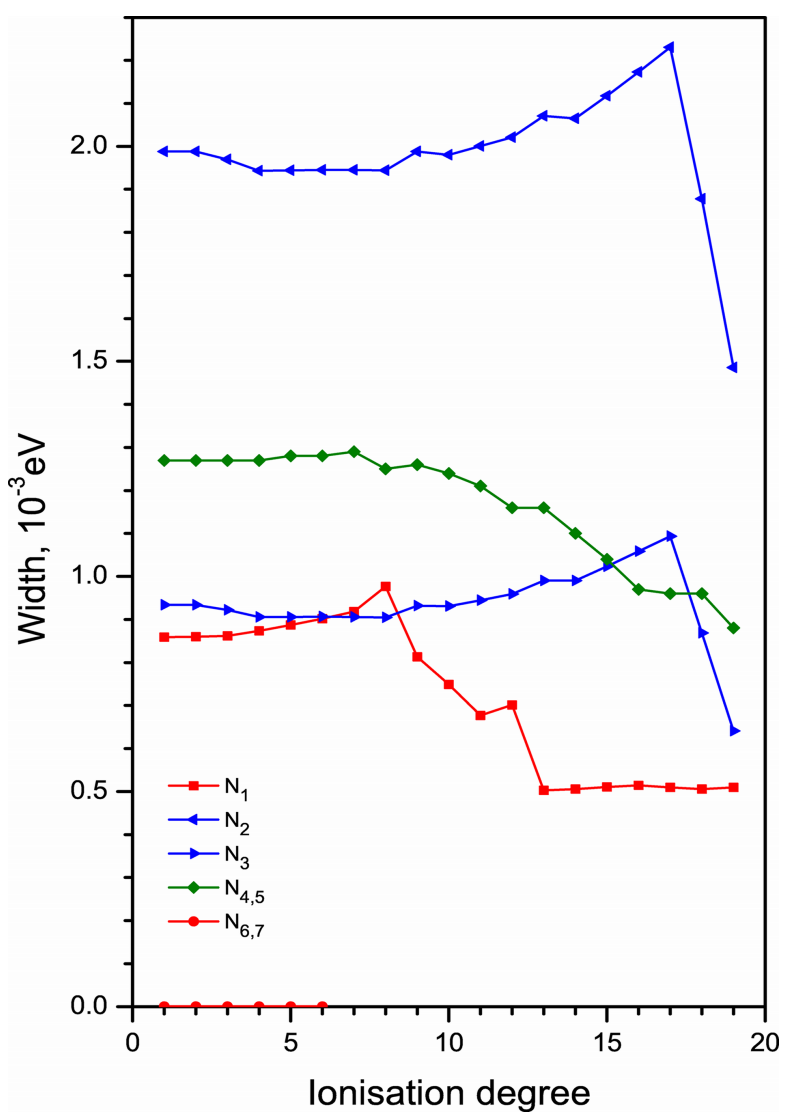

Fig. 4. Dependence of $\mathrm{N}_{1}, \mathrm{~N}_{2}, \mathrm{~N}_{3}, \mathrm{~N}_{4,5}$, and $\mathrm{N}_{6,7}$ radiative widths on ionisation degree.

the disappearance of electrons in $5 \mathrm{~s}$ shell. The similar two downfalls in the variation of $\Gamma_{\text {rad }}\left(N_{1}\right)$ width are caused by the beginning ionisation of the $5 \mathrm{p}^{N}$ shell and its full ionisation. Only the $\Gamma_{\text {rad }}\left(N_{4,5}\right)$ width changes almost monotonically, because the main contribution to this quantity is given by transitions from the $4 \mathrm{f}^{N}$ shell containing a large number of electrons $(N=14$ or 13).

The $\mathrm{N}_{i}$ fluorescence yield $\omega_{i}$ for tungsten ions up to $\mathrm{W}^{16+}$ is of order of $10^{-5}-10^{-2}$ (Fig. 5). Its values for $i=1-5$ remain almost constant at small ionisation stages. At $q=1$ our values of $\omega_{i}$, as well as the Auger yields $S_{i j}$, approximately correspond to calculation results given in [19]. It is necessary to note that later published data [7], obtained by fitting with polynomials the results of [19], essentially differ from the latter for the very elements the data of which were used, including tungsten.

\section{Conclusions}

We have determined the intervals of ionisation degrees in which the CK transitions for the vacancy states in $\mathrm{N}_{i}$ subshells of tungsten are possible or partially possible.

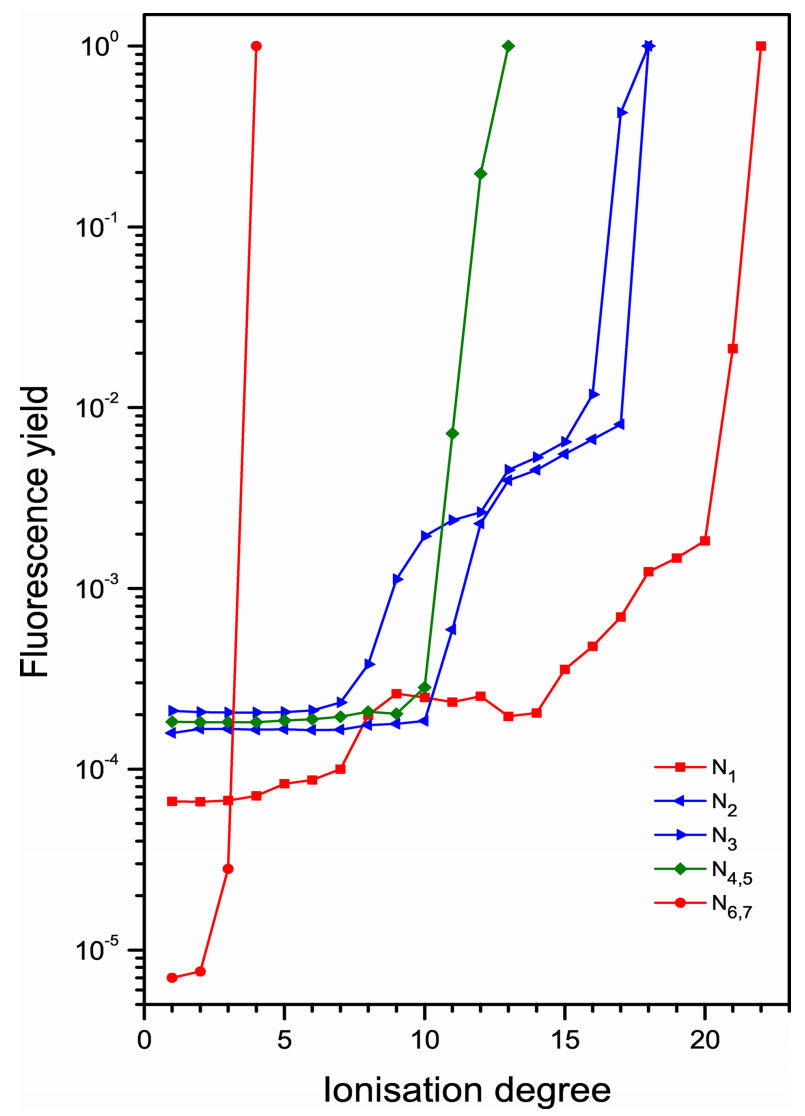

Fig. 5. Dependence of $\omega_{1}, \omega_{2}, \omega_{3}, \omega_{4,5}$, and $\omega_{6,7}$ fluorescence yields on ionisation degree.

The energy level spectra of configurations with such vacancies and outer open shells extend up to several tens of $\mathrm{eV}$, thus the case of overlapping initial and final configurations is rather frequent and the partially possible Coster-Kronig transitions can take place in several ions successively. At small ionisation degrees various $\mathrm{CK}$ and $\mathrm{sCK}$ transitions are permitted and the Auger width as well as the practically equal to it total natural width obtains a rather large value; but at ionisation stages from about 7 a sudden decrease of width takes place due to energetic interdiction of the most probable Auger transitions. The $\omega_{1}-\omega_{5}$ fluorescence yields have very small, almost constant value, approximately equal to $10^{-4}$, at ionisation degrees up to $7-10$; for higher ions its value significantly increases.

Only the calculated natural widths for single ions can be compared with experimental values as well as with results of calculations in other approximations. Our results correspond better to experimental values than the ones calculated by relativistic Dirac-Fock-Slater [21] or nonrelativistic Hartree-Fock-Slater [18] methods. However, for all shells except $\mathrm{N}_{6,7}$, the single configuration calculation significantly overestimates experimental data. The configuration interaction effects tend 
to become weaker with ionisation degree, thus a better correspondence of calculated and experimental results for higher ions can be supposed.

The indicated regularities of Coster-Kronig and fluorescence yields variation in isonuclear sequence can be characteristic also for the ions of other elements.

\section{Acknowledgements}

This work was partly supported by the Research Council of Lithuania, Contract No. MIP-61/2010. The support was also obtained from the European Commission under the contract of Association between EURATOM and Lithuanian Energy Institute within the framework of the European Fusion Development Agreement No. FU07-CT-2007-00063.

\section{References}

[1] G. Zschornack, Handbook of X-Ray Data (Springer, Berlin, 2007).

[2] Atomic Inner-Shell Physics, ed. B. Crasemann (Plenum Press, New York, 1985).

[3] S. Puri and N. Singh, Rad. Phys. Chem. 75, 2232-2238 (2006).

[4] J.L. Campbell, At. Data Nucl. Data Tables 95, 115-124 (2009).

[5] Y. Chauhan and S. Puri, At. Data Nucl. Data Tables 94, 38-49 (2008).

[6] J.L. Campbell and T. Papp, At. Data Nucl. Data Tables 77, 1-56 (2001).

[7] O. Sogut, J. Quantum Spectrosc. Radiat. Transfer 90, 239-252 (2005).
[8] V. Horvat, R.L. Watson, and J.M. Blackadar, Nucl. Instrum. Methods B 170, 336-346 (2000).

[9] A.G. Kochur, D.I. Dudenko, V.L. Sukhorukov, and I.D. Petrov, J. Phys. B 27, 1709-1721 (1994).

[10] F.P. Larkins, J. Phys. B 4, L29-L31 (1971).

[11] D. Banaś, J. Braziewicz, M. Czarnota, I. Fijał, M. Jaskóła, A. Korman, W. Kretschmer, M. Pajek, and J. Semaniak, Nucl. Instrum. Methods B 205, 139-143 (2003).

[12] Ch. Biedermann, R. Radtke, R. Seidel, and T. Pütterich, Phys. Scripta T134, 014026 (2009).

[13] S.D. Loch, J.A. Ludow, M.S. Pindzola, A.D. Whiterford, and D.C. Griffin, Phys. Rev. A 72, 052716 (2005).

[14] R.D. Cowan, The Theory of Atomic Structure and Spectra (University of California, Berkeley, 1981).

[15] T. Pütterich et al., Plasma Phys. Contr. Fusion 50, 085016 (2008).

[16] H.P. Summers, The ADAS-Manual, www.adas.ac.uk/ manual.php .

[17] A.E. Kramida and J. Reader, At. Data Nucl. Data Tables 92, 457-479 (2006).

[18] R. Karazija, Introduction to the Theory of X-ray and Electronic Spectra of Free Atoms (Plenum Press, New York, 1996).

[19] E.J. McGuire, Phys. Rev. A 9, 1840-1851 (1974).

[20] F.Herman and S.Skillman, Atomic Structure Calculations (Prentice-Hall, Englewood Clifs, 1963).

[21] S.T. Perkins, D.E. Cullen, M.H. Chen, J.H. Hubbell, J. Rathkopf, and J.H. Scofield, Tables and Graphs of Atomic Subshell Relaxation Data derived from the LLNL Evaluated Atomic Data Library, Lawrence Livermore National Laboratory report UCRL-504000, Vol. 30, 1991.

[22] M. Ohno and G. Wendin, Phys. Rev. A 31, 2318-2330 (1985).

\title{
COSTERIO IR KRONIGO ŠUOLIŲ DRAUDIMAS IR FLUORESCENCIJOS BEI AUGER IŠEIGOS VOLFRAMO IZOBRANDUOLINĖJE SEKOJE
}

\author{
S. Kučas, R. Karazija \\ Vilniaus universiteto Teorinès fizikos ir astronomijos institutas, Vilnius, Lietuva
}

\begin{abstract}
Santrauka
Auger šuoliai yra plačiai nagrinèti eksperimentiškai ir teoriškai atomams su vidine vakansija. Tuo tarpu duomenų jonams yra labai mažai, nėra tirti šių šuolių kitimo dèsningumai izobranduolinėse sekose. Darbe toks nagrinejjimas atliktas volframui, kurio spektriniai tyrimai yra aktualūs dèl šio elemento naudojimo termobranduolinès sintezès reaktoriaus - tokamako konstrukcijose. Atlikti sistemingi Auger ir fluorescencijos išeigų, lygmenų Auger bei radiaciniu plo-
\end{abstract}

čiu skaičiavimai volframo jonams su $4 l^{-1}(l=\mathrm{s}, \mathrm{p}, \mathrm{d}, \mathrm{f})$ vakansija iki jonizacijos laipsnių, kuriems esant Auger šuoliai tampa nebegalimi. Šios charakteristikos stipriai priklauso nuo labiausiai tikètinų Costerio ir Kronigo šuolių, todèl nustatyti jonizacijos laipsniu intervalai, kuriuose šie šuoliai yra galimi energetiškai. Nustatyta ir aptarta Auger šuoliu pagrindinių charakteristiku priklausomybè nuo jonizacijos laipsnio ir vakansijos tipo. 